\title{
The efficacy and safety of Rosuvastatin versus Atorvastatin, a double blind, randomized control study and comparison in patients with dyslipidemia
}

\author{
Dr.R.Suryanarayana Raju ${ }^{1}$, Dr.Ch.Ratna Kumar ${ }^{1}$, Dr.G.Vijaya Kumar ${ }^{1}$, \\ Dr.G.V.Benerji ${ }^{1}$,Dr.G.Srilaxmi ${ }^{1}$, M.Farid Babu ${ }^{2}$, D.Rekha Kumari ${ }^{2}$ \\ ${ }^{1}$.Associate Professor ,Department Of Pharmacology, Konaseema Institute Of Medical Sciences and Research \\ Foundation(KIMS \& RF),Amalapuram,E.G dist,Andhra Pradesh. \\ ${ }^{1}$. Associate Professor,Department Of Biochemistry,GEMS,Srikakulam,Andhra Pradesh \\ ${ }^{1}$. AssistantProfessor, Department Of Biochemistry, Rangaraya MedicalCollege, Kakinada,E.G.dist,Andhra \\ Pradesh \\ ${ }^{1}$.Professor, Department of Biochemistry, Konaseema Institute Of Medical Sciences andResearch \\ Foundation(KIMS \& RF),Amalapuram,E.G dist,Andhra Pradesh. \\ ${ }^{1}$.Assistant Professor,Department Of Biochemistry,Rangaraya Medical College, Kakinada,E.G.dist,Andhra \\ Pradesh \\ ${ }^{2}$.Assistant Professor,Department Of Biochemistry, Konaseema Institute Of Medical Sciences and Research \\ Foundation(KIMS \& RF),Amalapuram,E.G dist,Andhra Pradesh \\ ${ }^{2}$.Assistant Professor,Department Of Biochemistry, Konaseema Institute Of Medical Sciences and Research \\ Foundation(KIMS \& RF),Amalapuram,E.G dist,Andhra Pradesh
}

\begin{abstract}
The Present study was a double blind randomized comparative study of Rosuvastatin versus Atorvastatin in patients with dyslipidemia at Rangaraya Medical College,Government General Hospital, Kakinada, A.P India. The total 50 patients aged $35-70$, were enrolled into the study group and 50 age, sex matched healthy individuals were enrolled as control group and they were analysed for the lipid profiles. The study group was randomly allocated into 2 groups as group $A(n=25)$ and group $B(n=25)$. GroupA received the drug Rosuvastatin 10mg and the groupB received the drug Atorvastatin 10mg. The patients were followed for 12 weeks. . There were no drop outs in both the study groups in the present study. Comparison was made regarding the reduction in the $L D L-C$, Total cholesterol, VLDL-C and Triglycerides, and improvement of of $H D L-C$, and side effects. Statistical analysis was done using the paired student ' $t$ ' test for comparing the lipid profiles of the two groups before and after treatment. The results of the study showed that Rosuvastatin is better than Atorvastatin to treat dyslipidemias in terms of efficacy in lowering the lipid profiles and more safer for side effects.
\end{abstract}

Key words: Rosuvastatin, Atrovastatin, dyslipidemia

\section{Introduction:}

Dyslipidemias are disorders of lipoprotein metabolism including lipoprotein overproduction and deficiency. They may manifest as one or more of the following: elevated levels of total cholesterol, low density lipoprotein cholesterol(LDL), and triglyceride levels or as decreased levels of high density lipoprotein cholesterol (HDL) ${ }^{1}$.Dyslipidemias are closely associated with atherosclerosis and is the major causal factor in the development of ischemic diseases. Ischemic cardiovascular and crebrovascular events are the leading causes of morbidity and mortality ${ }^{2}$. Dyslipidemias are classified into primary (familial hypercholesterolemia) and secondary dyslipidemias (disease states: hypothyroidism, nephritic syndrome, obesity, diabetes, alcoholism and drugs: thiazides, beta blockers, prednisone, progestins, oestrogens and anabolicsteroids) ${ }^{3}$. The benefits of treating hyperlipidemia are that we can reduce the chances of mortality, coronary events like myocardial infarction and stroke ${ }^{2,4 .}$ Over the past decade, the use of statins or HMG-COA reductase inhibitors for the treatment of hypercholesterolemia has revolutionized physician's ability to slow the progression of CHD ${ }^{5}$.The broad range of significant clinical benefits of statin therapy include a decrease in major coronary events, coronary revascularization, stroke\& TIA, death due to CHD, \& total mortality ${ }^{4}$.

\section{Review of Literature:}

Elevated levels of Total cholesterol and triglycerides showed the decrease in HDL-C ${ }^{5}$.According to Lawrence et al, 2007, there is a strong relation between decrease of LDL-C causes a decreased risk of CHD. ${ }^{6}$.The main Lipids and Lipoproteins are cholesterol, triglyceride and phosphholipid.Endogenous synthesis of cholesterol in the liver is controlled by the rate limiting step involving the microsomal enzyme 3-hydroxy-3- 
methylglutaryl-COA(HMG-CoA) reductase. Lipids are transported in plasma as lipoproteins, which play an important role in the regulation of lipid transport and lipoprotein metabolism. They are classified on the basis of their densities as chylomicrons, VLDL, IDL,LDL,HDL.

\section{Materials and methods:}

Subjects participating in the research study were informed for consent as per the Helsinki declaration1977, and clinical history was collected through a structured questionare. Fasting blood samples were collected from Control and study group subjects and suitable anticoagulant was added and plasma was separated and used for further analysis. Total cholesterol was estimated by CHOD-PAP method. Triglycerides were measured by GPO method. HDL-C was measured by Phosphotungstic acid method. Results were obtained from ERBA CHEM 7 Semiautoanalyzer. VLDL was calculated by Friedewald's calculation. Results were expressed as mean $\pm \mathrm{SD}$, before and after treatment the parameters were again measured by paired student ' $\mathrm{t}$ ' test. $\mathrm{T}$ and $\mathrm{p}$ value are calculated and 0.05 are considered as statistically significant. SGOT \& SGPT were measured by kinetic mode by semi auto analyser.

\section{Exclusion criteria:}

Patients with serious hypersensitivity to statins, severe CHF, Malignancy,hypothyroidism, history with chronic alcoholism, systemic illness, women in breast feeding were excluded from the study.

\section{Inclusion criteria:}

Age groups between 35 - 70, willing for research trial, were enrolled in the present study .

\section{Results and Discussion:}

The mean baseline TC in group A and group B are 220.20 $\pm 9.4(\mathrm{SD}) \mathrm{mg} / \mathrm{dl}$, where $\mathrm{P}>0.05(\mathrm{i} . \mathrm{e} \mathrm{P}=0.0524$ ) in the mean baseline TC values between the two groups and they are comparable. At the end of study, the mean $\mathrm{TC}$ at 12 weeks in group $\mathrm{A}$ and group B are 193.39 $\pm 9(\mathrm{SD}) \mathrm{mg} / \mathrm{dl}$ and 203.21 \pm 7.9(SD)mg/dl respectively. So there is a statistically significant difference at the end of the study where $\mathrm{P}<0.05$ (i.e. $\mathrm{P}=0.001$ ) between two groups. Overall the mean drop in TC in group A and group B are $26.81 \mathrm{mg} / \mathrm{dl}$ and $21.76 \mathrm{mg} / \mathrm{dl}$. The percentage drop in mean TC in group A and B are $12.17 \%$ and $9.6 \%$ respectively. The mean baseline TG in group A and group $\mathrm{B}$ were $315.52 \pm 18.06(\mathrm{SD}) \mathrm{mg} / \mathrm{dl}$ respectively. There is no significant difference where $\mathrm{P}>0.05$ (i.e. $\mathrm{P}=0.676$ ) in the mean baseline values between the two groups and they are comparable. At the end of the study, the mean TG at $12 \mathrm{wks}$ in group A and group B are 281.64 \pm 25.02 (S.D)mg/dl and $295.72 \pm 17.05$ (S.D)mg/dl respectively. So there is statistically significant difference at the end of the study where $\mathrm{P}<0.05(\mathrm{i} . \mathrm{e}$. $\mathrm{P}+0.0136)$ between the two groups. Overall the mean drop in TG in group A and group B are $31.23 \mathrm{mg} / \mathrm{dl}$ and $19.8 \mathrm{mg} / \mathrm{dl}$. The percentage drop in mean TG in group $\mathrm{A}$ and $\mathrm{B}$ are $9.98 \%$ and $6.6 \%$ respectively. The mean baseline HDL$\mathrm{C}$ in group $\mathrm{A}$ and group $\mathrm{B}$ are $28.87 \pm 7.492(\mathrm{SD}) \mathrm{mg} / \mathrm{dl}$. There wass no significant difference where $\mathrm{P}>0.05$ (i.e. $\mathrm{P}=0.385)$ in the mean baseline HDL $-\mathrm{C}$ values between the two groups and they are comparable. At the end of the study the mean HDL-C at 12weeks in group A and group B are 33.8 $\pm 7.874(\mathrm{SD}) \mathrm{mg} / \mathrm{dl}$ and 29.43 \pm 6.669 (SD) $\mathrm{mg} / \mathrm{dl}$ respectively. So there is statistically significant difference at the end of the study where $\mathrm{P}<0.05$ ( i.e. $\mathrm{P}=0.0241$ ) between the two groups. Overall the mean increase in HDL-C in group A and group B are $4.93 \mathrm{mg} / \mathrm{dl}$ and $2.10 \mathrm{mg} / \mathrm{dl}$. The percentage drop in mean TC in group A and B are $4 \%$ and $2 \%$ respectively. The mean baseline LDL-C levels in group A and group B were $134.373 \pm 4.828(\mathrm{SD}) \mathrm{mg} / \mathrm{dl}$ respectively. There is no significant difference where $\mathrm{P}>0.05$ (i.e. $\mathrm{P}=0.2123$ ) in the mean baseline $\mathrm{LDL}-\mathrm{C}$ values between the two groups and they are comparable. At the end of the study, the mean LDL-C at 12 weeks in group A and group B are $112.05 \pm 4.543(\mathrm{SD}) \mathrm{mg} / \mathrm{dl}$ and $116.49 \pm 4.507(\mathrm{SD}) \mathrm{mg} / \mathrm{dl}$ respectively. So there is statistically significant difference at the end of the study where $\mathrm{P}<0.05$ (i.e. $\mathrm{P}=0.0003$ ) between the two groups. Overall the mean drop in LDL $-\mathrm{C}$ in group A and group B are $20.44 \mathrm{mg} / \mathrm{dl}$ and $17.88 \mathrm{mg} / \mathrm{dl}$. The percentage drop in mean LDL-C in group $\mathrm{A}$ and $\mathrm{B}$ are $15.42 \%$ and $13.3 \%$ respectively.There was no significant difference in the SGOT, group A and B $31 \pm 9.2,30.9 \pm 9.2,31.91 \pm 9.1$ respectively and SGPT levels in group A and B before26.3 \pm 9.1 after treatment $26.5 \pm 9.0,26 \pm 9.0$ respectively with Resuvastatin and Atrovastatin. Both the drugs are equally safe (Tables-1, $2 \& 3$ ).

There was a strong relation between CHD and dyslipidemias ${ }^{\mathbf{5 , 6}}$. Hyperlipoproteinemias are the underlying cause of lipidemias ${ }^{\mathbf{7 , 8}}$. ATP III recognized that LDL lowering is the primary surrogate end point toward reducting in the CVD events and mortality ${ }^{\mathbf{9 1 0}}$. Statins are having anti inflammatory roles ${ }^{\mathbf{1 1}, \mathbf{1 2}}$. Statins has a role in vasodilation functions ${ }^{\mathbf{1 3}}$, also has a role in chemotaxis for plaques, ${ }^{\mathbf{1 4}}$ and enhances vasoreactivity of unstable statins reduce effects in plaques formation, ${ }^{15,16}$. Statins effects the leucocyte migration, ${ }^{17,18}$ and role in endothelium function ${ }^{\mathbf{1 9}}$. Also inhibit growth and proliferation of macrophages ${ }^{\mathbf{2 0}}$.Statins induce apoptosis and retard hyperplasia and re-stenosis, provide plaque stability ${ }^{\mathbf{2 1 , 2 2}}$, statins decrease T-cell proliferation ${ }^{\mathbf{2 3}}$.Statins 
improve endothelial dysfunction by increasing nitric oxide bioavailability and reducing LDL oxidation and vascular inflammatory response. Statins increase the concentration of nitric oxide which has vasodilator, antithrombotic and antiproliferative properties ${ }^{24}$. Suppress superoxide formation and enhances $\mathrm{NO}$ generation by vascular endothelial cells via inhibition of Rac and $\mathrm{Rho}^{25}$. Rosuvastatin has been shown to increase vascular endothelial NO production and attenuate myocardial necrosis following ischemia and reperfusion in mice ${ }^{26}$. Statins decrease the LDL oxidation by increasing NO which can scavange superoxide free radical anions responsible for LDL oxidation ${ }^{27}$. Antioxidant actions of No antagonizes the vasoconstrictive properties of the Reactive oxygen species(ROS). Reduces lipid peroxidation and ROS production ${ }^{28}$.Plaque stability of statins stabilize plaque by inhibiting metalloproteinases, which play a potential role in atheromatous plaque disruption ${ }^{29,30}$.Statins has coagulation function and inhibit extrinsic coagulation pathway, inhibit platelet adhesion and maintain a balance between prothrombotic and fibrinolytic mechanisms ${ }^{31}$. NO by its sympathoinhibitory action reduce angiotensin II and AT1 receptor expression ${ }^{32,33}$ in Glomerulonephritis: reduce monocyte infiltration \& expression of vascular cell adhesion molecule(VCAM-1). Reducess proteinuria ${ }^{34}$,and has antiproliferative effects in cancers ${ }^{35}$

V. Tables:

Table.1Levels of Lipid profile in Control group and Study group

\begin{tabular}{|l|l|l|}
\hline Parameters & Control $(\mathbf{n}=\mathbf{5 0})$ & Study group $(\mathbf{n}=\mathbf{5 0})$ \\
\hline Total cholesterol $(\mathrm{mg} \%)$ & $155.0 \pm 11.0$ & $220 \pm 9.4$ \\
\hline HDL-C(mg\%) & $35.0 \pm 6.1$ & $28.0 \pm 7.4$ \\
\hline LDL-C(mg\%) & $83.0 \pm 12.0$ & $134.0 \pm 6.0$ \\
\hline Triglycerides(mg\%) & $71.0 \pm 19.0$ & $315.0 \pm 29.0$ \\
\hline VLDL(mg\%) & $23.0 \pm 7.0$ & $55.0 \pm 12.0$ \\
\hline SGOT(IU/L) & $22 \pm 6.1$ & $31 \pm 9.2$ \\
\hline SGPT(IU/L) & $24 \pm 5.1$ & $26.3 \pm 9.1$ \\
\hline
\end{tabular}

Table.2 Lipid profiles of group A, before and after treatment of Rosuvastatins.

\begin{tabular}{|l|l|l|l|l|}
\hline Parameters & Before treatment & After treatment & ' $\mathbf{t}$ ' value & 'p' value \\
\hline Total cholesterol $(\mathrm{mg} \%)$ & $220 \pm 9.4$ & 193.39 .0 & 1.9 & 0.05 \\
\hline HDL-C $(\mathrm{mg} \%)$ & $28 \pm 7.4$ & $33 \pm 7.8$ & 2.3 & 0.02 \\
\hline LDL-C (mg\%) & $134 \pm 6.0$ & $112 \pm 4.5$ & 3.8 & 0.0003 \\
\hline Triglycerides(mg\%) & $315 \pm 29.0$ & $281 \pm 25.0$ & 2.5 & 0.01 \\
\hline VLDL-C (mg\%) & $55 \pm 12.0$ & $46 \pm 8.0$ & 2.6 & 0.01 \\
\hline SGOT(IU/L) & $31 \pm 9.2$ & $30- \pm 9.1$ & 0.001 & $0.12, \mathrm{NS}$ \\
\hline SGPT(IU/L) & $26.3 \pm 9.1$ & 0.02 & $0.12, \mathrm{NS}$ \\
\hline
\end{tabular}

Levels are expressed as Mean $\pm \mathrm{SD}$, p-value $<0.05$ were considered as statistically significant

Table. 3Lipid profiles in group B, before and after treatment of Atrovastatin.

\begin{tabular}{|l|l|l|l|l|}
\hline Parameters & Before treatment & After treament & 't' value & 'p' value \\
\hline Totalcholesterol mg\%) & $220 \pm 9.4$ & $203 \pm 7.9$ & 0.4 & 0.6, NS \\
\hline HDL-C (mg\%) & $28.0 \pm 7.4$ & $29 \pm 6.0$ & 0.8 & $0.3, \mathrm{NS}$ \\
\hline LDL- C (mg\%) & $134 \pm 6.0$ & $116 \pm 4.5$ & 1.2 & $0.2, \mathrm{NS}$ \\
\hline Triglycerides (mg\%) & $315 \pm 29.0$ & $295 \pm 17.0$ & 0.4 & $0.67, \mathrm{NS}$ \\
\hline VLDL (mg\%) & $55 \pm 12.0$ & $50 \pm 5.0$ & 0.5 & $0.59, \mathrm{NS}$ \\
\hline SGOT (IU/L) & $31 \pm 9.2$ & $31 \pm 9.1$ & 0.3 & $0.2, \mathrm{NS}$ \\
\hline SGPT (IU/L) & $26.3 \pm 9.1$ & $26 \pm 9.0$ & 0.31 & $0.21, \mathrm{NS}$ \\
\hline
\end{tabular}

Levels are expressed as Mean $\pm \mathrm{SD}$, p-value $>0.05$ were considered as statistically significant

\section{Conclusion:}

The results of this study showed that Rosuvastatin is better than atorvastatin in terms of efficacy. Both drugs are equally tolerated and equally safe.

[1] Harrison's, Principles of Internal Medicine, $18^{\text {th }}$ Edition.

\section{Bibliography:}

[2] Translating evidence into policy for cardiovascular disease control in india. Gupta et al. Health research policy and systems; 2011,9:8

[3] Davidson's Principles and practice of Medicine, $22^{\text {nd }}$ edition.

[4] Lipids and stroke vol 3. May-june 2003, p170-176.

[5] Editional; Cardiology Today Nov-Dec 2007 voll, vol2.

[6] Lawrence M.Tierney et al. Current Medical diagnosis and treatment $11^{\text {th }}$ Edition. Ch 10:351-427.

[7] Joseph C. Witztlum, Goodman Gilmans, The pharmacological basics of therapeutics, $11^{\text {th }}$ edition.

[8] Bertram G. Katzung. 11 ${ }^{\text {th }}$ edition. Agents used in hyperlipidemia. Basics of clinical pharmacology ch35:581-595.

[9] The American Journal of medicine, Vol 112, issue 8, suppl 1, pg 8-10, june 2002. 
[10] Pubmed 1995 sep 2-9: 24(25); 1147-51.

[11] Bhatt DL, Topol EJ. Need to test the arterial inflammation hypothesis. Circulation 2002; 106:136-40.

[12] Bufffon A, Biasucci LM, Liuzzo G, D’Onofiro G, Crea F, Maseri A. widespread coronary inflammation in unstable angina. N Engl J Med 2002;347:5-12.

[13] Cew DP, Bhatt DL, Robbins MA, Penn MS, Schneider JP, Lauer MS, et al. Incremenntal prognostic value of elevated baseline creactive protein among established markers of risk in percutaneous coronary intervention. Circulation 2001;104:992-7.

[14] Verma S, Wang CH, Li SH, Dumont AS, Fedak PW, Badiwala MV, et al, A self- fulfilling prophecy:C-reactive protein attenuates nitric oxide production and inhibits angiogenesis. Circulation2002;102;1000-6.

[15] 15.Fichtlscherer S,Rosenberger G,Walter DH,Breuer S,Dimmerler S,Zeiher AM.Elevated C-reactive protein levels and impaired endothelian vasoreactivity in patients with coronary artery disease.Circulation 2000;102;1000-6

[16] Katritsis D, Korovesis S, Giazitzoglou E, Parissis J, Kalivas P, Webb-Peploe MM, et al. C-reactive protein concentnnratioins and angiographic charactreristics of coronary lesions. ClinChem 2001;47:882-6.

[17] Mitchell RN, Cotran RS. Cell injury, adaptation,, and death. In:Kumar V, Cotran RS, Robbins SL, editors. Robbins. Basic Pathology. $7^{\text {th }}$ ed. New Delh: Harcourt (india)Pvt. Ltd. 2003.

[18] Romano M, Mezzetti A Marulli C, CiavattoniG, febo F, Di lenno S, et al. fluvastatin reduces soluble P-selectin and ICAM-1 levels in hypercholesterolemic patients: Role of nitric oxide. J Investig Med 2000;48:183-9.

[19] Niwa S, Totsuka T, hayashi S. Inhibitory effect of fluvastatin, an HMG-CoA reductase inhibitor, on the expression of adhesion molecules on human monocyte cell line. Int J Immunopharmacol 1996;18:669-75.

[20] Shiomi M, Ito T. Effect of cerivastatin sodium a new inhibitor of HMG-CoA reductase, on plasma lipid levels, progression of atherosclerosis, and the lesional composition in the plaques of WHHL rabbits. Br JPharmacol1999; 126:961-8.

[21] Guijarro C, Blanco-Colio LM, Ortego M, Alonso C, Ortiz A, Plaza jj, et al. HMGCoA reductase inhibitors induce apoptosis of vascular smooth muscle cells in culture. Circ Rws 1998;183:490-500.

[22] Inoue I, Goto S, Mizotani K, Awata T, Mastunaga T, Kawai S, et al. Lipophilic HMGCoA reductasse inhibitor has an antinflammatory effect: reduction of mRNA levels for interleukin, lbeta, IL -6, cox-2, and P22phox, by regulation ofPPAR alpha in primary endothelial cells. Life Sci 2000;67:863.76.

[23] Cutts JL, Bankhurst AD. Suppression of lymphoid,cell function invitro byinhibition of HMGC0A reductase by lovastatin. Int J Immunopharmacol 1989;11:863-9.

[24] Tademoto M, Liao JK. Pleiotropic effects of HMGCoA reductase inhibitors. Arterioscler Thromb Vasc Biiol 2001;1:1712-9.

[25] Laufs U, La Fata V, Plutzky J, Liao JK. Upregulation of endothelial nos by HMGCoA reductase inhibitors. Circulation 1998;47:1129-35.

[26] Pelat M DessyC, Massion P, desager JP, Feron O, Balligand Jl. Rosuvastatin decreases caveolin-1 and improves nitric oxide dependent heart rate and blool pressure variability in apolipoprotein E-/-mice invivo. Circulation2003;107:2480-6.

[27] Giroux LM, Davignon J,1 Naruszewicz M. Simavastatin inhibits the oxidation of low-density lipoproteins by activated human monocyte-derived macrophages. BiochemBoophysActa1993;1165:335-8.

[28] Wassmann S, Laufs U, Baaumer AT, Muller K, Ahlbory K, linz W, etal. HMGCoA reductase inhibitors improve endothelial sysfunnctionin normochholesterolemic hypertension via reduced production of reactive oxygen species. Hypertensison 2001;37:1450-7.

[29] Libby P, Ridker PM, Maseri A. Inflammaation and atherosclerosis. Circulation 2002;105:1135-43.

[30] Crisby M, Nordin-Fredriksson G, Shah PK, Yano J, Zhu J, Nilsson J. Pravastatin treatment increases collagen content and decreases lipid content, inflammation, metalloproteinases, and cell death in human carotid plaques: Implications for plaque stabilization. Circulation 2001;1103:L926-33.

[31] Rosenson RS, Tangney CC. Antiatherothrombotic properties of statins: Implications for cardiovascular event reduction. JAMA1998;279:1643-50.

[32] Glorisos N, Troffa C, Filigheddu J,, Dettori f, Soro A, Parpaglia PP, et al. Effect of the HMGCoA reductase inhibitors on blood pressure ion patients wit essential hypertension and primary hyperchholesterolemia. Hypertension1999;34: 1281-6.

[33] Vaughan CJl, Delanty N. Neuroprotective properties of statins in cerebral ischemia and stroke. Stroke 1999;30:1969-73.

[34] Buemi M, Allegra A Corica F, Aloisi C, Giacobbe M, Pettinato G, etal. Effect of fluvastatin on proteinuria in patients with immunoglobulin A nephropathy. Clin Pharmacol Ther 2000;67:427-31.

[35] denoyelle C, Vasse M,, Korner m, Mishal Z, Ganne F, Vanniier JP, etal. Cerivastatin, inhibits the signaling pathways involved in the invasiveness and metastatic properties of highly invasive breast cancer cell lines: an in vitro study. Carcinogenesis 2001;22:1139-48. 